\title{
Corrigendum: Cross-Talk between Staphylococcus aureus and Other Staphylococcal Species via the agr Quorum Sensing System
}

\author{
Jaime Canovas ${ }^{1 \dagger}$, Mara Baldry ${ }^{1 \dagger}$, Martin S. Bojer ${ }^{1 \dagger}$, Paal S. Andersen ${ }^{1,2}$, \\ Piotr K. Grzeskowiak ${ }^{3}$, Marc Stegger ${ }^{2}$, Peter Damborg ${ }^{1}$, Christian A. Olsen ${ }^{3}$ and \\ Hanne Ingmer ${ }^{1 *}$ \\ ${ }^{1}$ Department of Veterinary Disease Biology, Faculty of Health and Medical Sciences, University of Copenhagen, \\ Frederiksberg, Denmark, ${ }^{2}$ Department of Microbiology and Infection Control, Statens Serum Institut, Copenhagen, Denmark, \\ ${ }^{3}$ Center for Biopharmaceuticals and Department of Drug Design and Pharmacology, Faculty of Health and Medical Sciences, \\ University of Copenhagen, Copenhagen, Denmark
}

Keywords: Staphylococcus aureus, Staphylococcus schleiferi, quorum sensing, agr, quorum sensing inhibition, auto-inducing peptide, cross-talk, anti-virulence therapy

\section{OPEN ACCESS}

Edited by:

Susanne Fetzner,

Universität Münster, Germany

Reviewed by:

Susanne Fetzner,

Universität Münster, Germany

Mattias Collin,

Lund University, Sweden

${ }^{*}$ Correspondence: Hanne Ingmer

hi@sund.ku.dk

tThese authors have contributed equally to this work.

Specialty section: This article was submitted to Systems Microbiology, a section of the journa Frontiers in Microbiology

Received: 10 April 2017 Accepted: 29 May 2017 Published: 08 June 2017

Citation: Canovas J, Baldry M, Bojer MS, Andersen PS, Grzeskowiak PK,

Stegger M, Damborg P, Olsen CA and Ingmer $H$ (2017) Corrigendum: Cross-Talk between Staphylococcus aureus and Other Staphylococcal Species via the agr Quorum Sensing System. Front. Microbiol. 8:1075. doi: 10.3389/fmicb.2017.01075

\section{A corrigendum on}

Cross-Talk between Staphylococcus aureus and Other Staphylococcal Species via the agr Quorum Sensing System

by Canovas, J., Baldry, M., Bojer, M. S., Andersen, P. S., Grzeskowiak, P. K., Stegger, M., et al. (2016). Front. Microbiol. 7:1733. doi: 10.3389/fmicb.2016.01733

It has come to our attention that in Figure $\mathbf{4 B}$ of the original article, we stated that the S. schleferi autoinducing peptide has the sequence YPFCIAYF. This peptide was synthesized, tested and found to have inhibitory activity. However, the correct AIP sequence is YPFCIGYF. We have now synthesized this peptide with the protocol stated below, which differs from the one published, and have tested the correct peptide for activity. As demonstrated below, we find that the new peptide has strong agr inhibitory activity, as expected, and, therefore, the conclusions of the paper remain the same.

\section{MATERIALS AND METHODS}

\section{Chemical Synthesis of S. schleiferi AIP}

The S. schleiferi AIP was synthesized applying a strategy based on the C-terminal peptide $\mathrm{N}$-acylbenzimidazolinone $(\mathrm{Nbz})$ derivative (Blanco-Canosa and Dawson, 2008), which was previously reported by Blackwell and coworkers (Tal-Gan et al., 2016) for AIP syntheses. Briefly, the linear peptide $(20.0 \mu \mathrm{mol})$ was synthesized on 3-(Fmoc-amino)-4-aminobenzoyl aminomethyl polystyrene resin (Dawson Dbz AM resin; 0.49 mmol/g, Merck) by automated Fmoc solid-phase peptide synthesis (SPPS) as described in the Materials and Methods of the manuscript. The peptide $(5.00 \mu \mathrm{mol})$ was then cyclized by Nbz formation, TFA-mediated cleavage from the resin, and stirring in aqueous guanidinium chloride ( $6 \mathrm{M}$ in $0.1 \mathrm{M}$ phosphate buffer, $\mathrm{pH}=6.8)-\mathrm{MeCN}(6: 4)$ for $2 \mathrm{~h}$ at $50^{\circ} \mathrm{C}$ (Tal-Gan et al., 2016). Cyclization was followed by purification as described in our manuscript to give the title compound as a white fluffy solid (1.9 mg, 28\%).

Purity: $>98 \%$ as determined by UPLC-MS analysis at $230 \mathrm{~nm}$.

MS: $\mathrm{m} / \mathrm{z}$ calcd for $\mathrm{C}_{52} \mathrm{H}_{62} \mathrm{~N}_{8} \mathrm{O}_{10} \mathrm{~S}$ 991.4. ESI-MS found $991.4\left[\mathrm{M}+\mathrm{H}^{+}\right]$. MALDI-TOF MS found $991.5\left[\mathrm{M}+\mathrm{H}^{+}\right]$. 
B

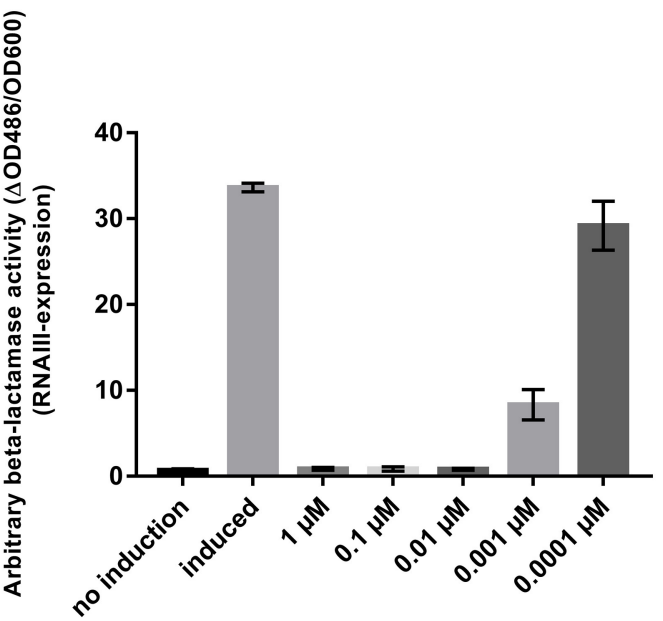

Synthetic S. schleiferi AIP challenge concentration

FIGURE 4 | S. schleiferi AIP interferes with S. aureus agr. (B) P3-blaZ expression recorded from S. aureus RN10829(P2-agrA:P3-blaZ)/pagrC-I (WT) when the inducing AIP-I containing supernatant (10\%) is challenged for $45 \mathrm{~min}$ with different concentrations of synthetic $S$. schleiferi AIP at indicated concentrations. No induction and AIP-I containing supernatant alone were included as controls. Each bar represents the average of 3 biological replicates and the error bars represent the standard deviation.

\section{$\beta$-Lactamase Assay and Inhibitory Concentration $\left(\mathrm{IC}_{50}\right)$}

The method used is described by Nielsen et al. (2014). Briefly, the RN10829 (P2-agrA:P3-blaZ)/pagrC-I (WT) and
RN10829(P2-agrA:P3-blaZ)/pagrC-I-R23H (AgrC const.) reporter strains were grown to an $\mathrm{OD}_{600}$ of $0.4-0.5$ where a $1 / 10$ volume of AIP-I containing supernatant (obtained from strain 8325-4) and $1 / 10 \mathrm{~S}$. schleiferi supernatants were added to the reporter strain culture. In assays using heterologously expressed AIP $_{\text {Ss }} 1 / 20$ volume of AIP-I containing supernatant was challenged with $1 / 5$ volume supernatant from expression cultures. Samples obtained at $30 \mathrm{~min}$ time intervals after addition of test solutions were analyzed for $\beta$-lactamase activity by nitrocefin conversion. The $\mathrm{IC}_{50}$ of the selected S. schleiferi supernatants was also tested using the $\beta$-lactamase assay, where a $1 / 10$ volume $(0.5 \mathrm{~mL})$ of supernatant was added to the total volume of $5 \mathrm{~mL}$ of the reporter strain culture (RN10829-WT) representing the undiluted supernatant (100\%). Then, 80, $60,40,20,10,5,2.5$ and $2 \%$ of the initial volume of the selected supernatant was added to obtain the $\mathrm{IC}_{50}$ curve. Statistical analysis was performed using the Student's $t$-test (2-tailed).

\section{RESULTS}

\section{S. schleiferi Inhibition of $S$. aureus agr Is AIP-Mediated}

To support that the $S$. schleiferi AIP that is responsible for inhibition of $S$. aureus RNAIII via AgrC agonist activity, we synthesized the $S$. schleiferi AIP with the sequence YPFCIGYF and tested the synthetic compound in the P3-blaZ reporter strain. Our results in this amended Figure 4B show that the $S$. schleiferi AIP is a potent inhibitor of $S$. aureus RNAIII expression and that it acts antagonistically on the reporter strain at low nanomolar concentrations.

\section{REFERENCES}

Blanco-Canosa, J. B., and Dawson, P. E. (2008). An efficient Fmoc-SPPS approach for the generation of thioester peptide precursors for use in native chemical ligation. Angew. Chem. Int. Ed. 47, 6851-6855. doi: 10.1002/anie.200705471

Nielsen, A., Månsson, M., Bojer, M. S., Gram, L., Larsen, T. O., Novick, R. P., et al. (2014). Solonamide B Inhibits Quorum Sensing and Reduces Staphylococcus aureus Mediated Killing of Human Neutrophils. PLoS ONE 9:e84992. doi: 10.1371/journal.pone.0084992

Tal-Gan, Y., Ivancic, M., Cornilescub, G., and Blackwell H. E. (2016). Characterization of structural elements in native autoinducing peptides and non-native analogues that permit the differential modulation of AgrC-type quorum sensing receptors in Staphylococcus aureus. Org. Biomol. Chem. 14, 113-121. doi: 10.1039/c5ob01735a
Conflict of Interest Statement: The authors declare that the research was conducted in the absence of any commercial or financial relationships that could be construed as a potential conflict of interest.

Copyright (c) 2017 Canovas, Baldry, Bojer, Andersen, Grzeskowiak, Stegger, Damborg, Olsen and Ingmer. This is an open-access article distributed under the terms of the Creative Commons Attribution License (CC BY). The use, distribution or reproduction in other forums is permitted, provided the original author(s) or licensor are credited and that the original publication in this journal is cited, in accordance with accepted academic practice. No use, distribution or reproduction is permitted which does not comply with these terms. 